\title{
HRD CLIMATE IN VTPS AND KTPS - A STUDY
}

\section{DR. SHAIK KAMRUDDIN}

Assistant Professor, Department of Management Studies, Maulana Azad National Urdu University,

\author{
Hyderabad, Telangana, India
}

\begin{abstract}
Various Organizational factors formulate HRD climate such as the importance given by management towards Human Resource Development, freedom of employees, and various subsystems of HRD mechanisms. HRD climate profoundly influences the outlook, wellbeing, attitude and commitment of employees and plays a significant role in enhancing organizational performance. The present study aims to study the HRD climate existing in two public undertakings who have been pioneering disposition in spending for human resource development programs. The data has been collected from 607 employees using simple random sampling method. The findings of the study cover the perceptions of executives and non-executives on various aspects of General Climate, OCTAPACE culture and HRD mechanisms in VTPS and KTPS. The suggestions for better HRD practices and recommendations for improving HRD climate based on the findings are also discussed.
\end{abstract}

KEYWORDS: HRD Climate, OCTAPACE Culture, General Climate \& HRD Mechanisms

Received: Apr 15, 2019; Accepted: Jun 05, 2019; Published: Jun 19, 2019; Paper Id.: IJHRMRAUG20194

\section{INTRODUCTION}

'Human Resource' refers to the talents and energies of people who are available to some organisation as potential contributors to the creation and realization of the organisation's mission, vision and values and goals.

'Development' refers to a process of active learning from experience, leading to systematic and purposeful development of the whole person: body, mind and spirit. The development combines the concepts of development (change and growth) and training (learning specific skills).

Thus, HRD is the integrated use of training, organizational development, and career development efforts to improve individual, team and organizational effectiveness. Each one of the various activities that constitute HRD could be carried out in different ways; some ways of doing them would make HRD efforts more effective than some other ways of doing the same activities.

For making HRD effective, besides choosing the right activities, one must pay adequate attention to their process, too. Process refers to the specific style, method or the way in which a particular activity is implemented. The style, method or process of carrying out HRD activity is to be guided by the anticipated impact and ultimate concern for human dignity. Thus, HRD is a set of inter-related activities, by which human potentialities are assessed, selectively upgraded and appropriately deployed for achievement of envisioned goals, which foster human dignity. The term used to describe an integrated and holistic approach to changing work-related behaviour, using a range of learning techniques and strategies. 


\subsection{Significance of HRD Climate}

Of all the factors of production, man is by far the most important. The importance of human factor in any type of co-operation and endeavour cannot be over emphasized. It is a matter of common knowledge that every business organization depends for its effective functioning not so much on its material or financial resources as on its pool of able and willing human resources.

The organization becomes dynamic and growth oriented if their people are dynamic and proactive. Every organization can do a lot to make their people become dynamic and pro-active through people selection of such people and nurturing their dynamism and other competencies. Organization cannot survive beyond a point, unless they are continuously alert to the changing environment and continuously prepare their employees to meet the challenges and have an impact on the environment. Thus, HRD is an essential process for organisational growth.

Organizations face problems like high employee turnover rates, absenteeism, increasing the motivational levels, enhancing employee commitment, etc., which reflect the employee's satisfaction and morale. Various organizational policies, procedures, structures and systems decide the extent to which employees are satisfied in an organization. Most researchers agree that a congenial HRD climate is extremely important for the ultimate achievement of the HRD goals. It is a phenomenon experienced by employees and often referred to by expression like 'environment', 'atmosphere' and so on. The traditions, practices and culture, characteristic of each organization, all put together, make up the time for its members and profoundly influences their outlook, wellbeing, attitudes and their overall performance. Climate at the individual levels is a summary perception of the organization's work environment that is descriptive rather than evaluate in nature.

\subsection{Elements of HRD Climate}

This study focuses to investigate the HRD climate prevailing in two public sector companies with reference to three broad categories of HRD climate.

- General Climate

- OCTAPACE culture

- HRD Mechanisms

To begin with the general climate items, focus on the importance given to HRD by the top management and line managers, in general.

HRD mechanism indicates the extent to which various subsystems of HRD mechanism such as training, performance appraisal, potential appraisal, organization development, feedback and performance coaching, career planning, rewards, employee welfare, quality of work life and human resource information systems are implemented seriously (Rao, 1999).

The OCTAPACE items deal with the extent to which Openness, Confrontation, Trust, Autonomy, Pro-activity, Authenticity and Collaboration and Experimentation are valued and promoted in the organization.

These three groups were take with the following assumptions.

- A supportive climate overall is important for HRD to be effectively implemented. Such supportive climates consist of not only top management and line management's commitment but also good personnel policies and 
positive attitudes towards development;

- An integrated look at HRD and efforts to use as many HRD mechanisms as possible will result in the successful implementation of HRD. These mechanisms include: performance appraisal, potential appraisal, career planning, performance rewards, feedback and counselling training, employee welfare for quality work life, job-rotation etc.

- OCTAPACE culture is essential for facilitating HRD. Openness is present when employees feel free to discuss their ideas, activities and feelings with each other. Confrontation involves bringing problems and issues into the limelight with a view to solving them, rather than hiding them for fear of hurting or getting hurt. Trust is taking people at face value and believing them. Autonomy is the freedom to allow people to work independently with responsibility. Proactivity is encouraging employees to take initiative and risks. Authenticity is the tendency of interdependencies, to be helpful to each other and work as teams. Collaboration is required so the employees can cope up with the changes and upcoming trends in an organization.

\section{REVIEW OF LITERATURE}

These are extended literature which emphasizes the importance of HRD climate and practices for effective utilization of human resources. HRD plays a significant role in enriching the skills of employees (Tim Grieves, 2003). Pranabesh Ray (2004) observed that the chief objective of HRD is to build people who can enhance the growth and effectiveness of the organization. Ashit K. Sarkar (2004) felt that the organization's work culture, processes and environment affect the individual's potential along with ability, behaviour. Whereas, Badar Alam Iqbal (2006) stated that in order to face the issues and challenges of the 21 st century, one of the most strategic requirements is HRD as it is the major contributory factor in enhancing the efficiency and productivity resulting into profitability to organizations. Mufeed (2005), found that the value of authenticity had been well developed and signified Cohesion and trust in employees their personal relationship.

The findings of empirical studies conducted upon HRD practices across different industries supports these assumptions. Mishra K. (2003) found that there exists a positive correlation between HRD practices and performance of the LIC. Patel and Iyer (2004) identified that in the pharmaceutical industry the HRD is well planned and implemented, setting example for others to follow. Besides, the authors opined that employees are of the impression that they could acquire skills and improve themselves. Rodrigues (2005) found that the HRD Climate in the engineering institutes is highly satisfactory. Prakasha Rao, B.K.S. and Venkateswara Rao B.H (2005) stated that the success of LIC as a leading player in the market can be attributed to the HRD programmers undertaken by the LIC to its different cadres of employees.

Sonal Saxena (2006) felt that the major challenge faced by the IT industry is in the area of HRD. The IT industry can overcome the challenges by making the HRD activities consistent with the development efforts of their respective organizations. Srimannarayana M (2007) found that satisfactory HRD climate exists in the bank. He also found that OCTAPACE culture in the bank was superior to General HRD climate and the implementation of HRD mechanisms. Charles Moseley (2008)concludes that only by empowering employees, to accept the responsibility and to make decisions as fully active participants in the life of the organizations, can organizations hope to create the kind of responsiveness needed to meet the changing needs of customers in today's business environment. Kumudha and Abraham (2008) stated that programs allied to self-development, job openings, and prospects to acquire new abilities and retirement provision programs prominently stimulate the emotional state of career gratification. Saraswathi (2010), the research highlights that 
HRD-climate for IT is superior to Production companies. Mufeed and Hamdani (2013), asserted HRD climate and HRD mechanisms are dissatisfactory in case of health care sector of Jammu and Kashmir. Dr. Dolly Dolai (2015), in his study he analyzed HRD-climate of insurance companies for both private and public sector, and to understand the current position of HRD-climate.

\section{NEED AND SIGNIFICANCE OF THE STUDY}

The effective performance of an organization depends not just on the available resources, but its quality and competence as required by the organization from time to time. The difference in the level of performance of organizations depends on the utilization value of the human resources. The efficiency of the production process and various areas of management depend to a greater extent on the level of HRD. The organization can develop, change and excel, only if it possesses developed human resources. At the same time HRD helps in improving good human relations and positive organizational climate which in turn leads to the attainment of organizational goals economically and effectively.

Against this background, a study is planned to know the HRD Climates in Vijayawada Thermal Power Station (VTPS) and Kothagudem Thermal Power Station (KTPS), located in Vijayawada and Kothagudem. The study is significant as it ascertains the assessment of the HRD climate in the state owned big power sector units. It will be of immense help to the management of power plants, the State Governments for the formulation of HRD policies.

VTPS and KTPS are two major Public-Sector Undertakings who earned the distinction of being national award winners very often. VTPS and KTPS caters to the power needs of individuals, industries, government and various other organizations. It is to be worth mentioned public sector undertakings are the foremost in spending huge amounts on HRD. VTPS and KTPS have undertaken a good number of HRD measures such as employee welfare, organization development, performance appraisal etc. In fact, due to these various HRD measures their performance is quite commendable. Thus, this comparative study on HRD climate of these two prominent companies will make significant contributions for making the human resources vital, useful and purposeful.

\section{OBJECTIVES OF THE STUDY}

- $\quad$ To study the existing HRD practices in VTPS and KTPS

- To capture the perceptions of executives and non-executives on various aspects of General Climate in the organisations under study.

- To evaluate the perceptions of executives and non-executives with regard to OCTAPACE culture that prevails in both the organisations.

- To study the opinions and awareness of executives and non-executives on the execution of HRD mechanisms in VTPS and KTPS.

- To compare and analyse perceptual differences of executives and non-executives towards various aspects of HRD Climate in VTPS and KTPS.

\section{HYPOTHESIS OF THE STUDY}

The study is assumed to test the hypothesis, "there is no significant difference between HRD Climates of VTPS and KTPS". 
This hypothesis has been tested with the help of statistical technique 'One-way ANOVA'.

The mean values obtained from the two selected organizations for all the three individual dimensions 'General Climate', 'OCTAPACE Culture' and 'HRD Mechanisms' are considered in the test.

\section{METHODOLOGY AND DATA ANALYSIS}

The following sections present the methodology of the study.

\subsection{Selection of the Sample Respondents}

The researcher used simple random sampling without replacement to administer the questionnaire, to collect the information from the sample population of the two organizations under the study. A sample of 607 respondents which include 124 executives and 229 non-executives from VTPS and 94 executives and 160 non-executives from KTPS has been chosen. The details of the sample size are presented in the Table No:1. The sample from the VTPS is 353 and from KTPS is 254.

Table 1: Sample Size

\begin{tabular}{|l|c|c|c|c|}
\hline \multirow{2}{*}{$\begin{array}{c}\text { Employee } \\
\text { Category }\end{array}$} & \multicolumn{2}{|c|}{ VTPS } & \multicolumn{2}{c|}{ KTPS } \\
\cline { 2 - 5 } & $\begin{array}{c}\text { Sample (10\% } \\
\text { of Population) }\end{array}$ & Population & $\begin{array}{c}\text { Sample (10\% } \\
\text { of Population) }\end{array}$ & Population \\
\hline Executives & 124 & 1240 & 94 & 940 \\
\hline Non- Executives & 229 & 2290 & 160 & 1600 \\
\hline Total & 353 & 3530 & 254 & 2540 \\
\hline
\end{tabular}

\subsection{Collection of the Data}

Data for the study was collected from primary and secondary sources. HRD Climate questionnaire developed by T.V. Rao was used as the principal instrument for primary data collection. The questionnaire is divided into three parts: The first part comprises statements on General Climate (13 Statements, 1-13 of questionnaire), the second part covers the questions on OCTAPACE (10 statements, 14-23 of questionnaire) and the third part contains HRD Mechanisms (15 statements, viz., from 24-38 of questionnaire).

Secondary data includes annual reports, office records, fields, brochures and other published and unpublished material of the organization as well as books and government reports.

Table 2: Correlation Coefficient between Elements of HRD Climates in VTPS and KTPS

\begin{tabular}{|l|c|c|}
\hline \multicolumn{1}{|c|}{ Organisation } & $\begin{array}{c}\text { Correlation Coefficient } \\
\text { of VTPS }\end{array}$ & $\begin{array}{c}\text { Correlation Coefficient } \\
\text { of KTPS }\end{array}$ \\
\hline General Climate in VTPS & 1 & 0.97 \\
General Climate IN KTPS & 0.97 & 1 \\
\hline OCTAPACE Culture in VTPS & 1 & 0.95 \\
OCTAPACE Culture IN KTPS & 0.95 & 1 \\
\hline HRD Mechanism in VTPS & 1 & 0.98 \\
HRD Mechanism IN KTPS & 0.98 & 1 \\
\hline
\end{tabular}

Source: Primary Data

From the Table 2, it is inferred that there is high degree of positive correlation exists on General Climate in VTPS and KTPS. Regarding OCTAPACE culture and HRD Mechanism also there is high degree of positive correlation exists between VTPS and KTPS. 
Table 3: Comparative Position of HRD Climate in VTPS and KTPS

\begin{tabular}{|c|c|c|c|c|c|}
\hline \multirow{2}{*}{ Variables } & \multicolumn{2}{|c|}{ VTPS } & \multicolumn{2}{c|}{ KTPS } \\
\cline { 2 - 5 } & & Mean & \% & Mean & \% \\
\hline 1 & General Climate (X1) & 3.94 & 73.50 & 3.84 & 71.00 \\
\hline 2 & OCTAPACE Culture (X2) & 3.92 & 73.00 & 3.85 & 71.25 \\
\hline 3 & HRD Mechanism (X3) & 3.91 & 72.75 & 3.86 & 71.50 \\
\hline & Overall Mean & 3.92 & 73.00 & 3.85 & 71.25 \\
\hline
\end{tabular}

Source: Primary Data

The above mentioned Table 3 depicts the comparative position of the Human Resource Development Climate in VTPS and KTPS in terms of mean values and respective percentage scores with respect to the three variables viz., General Climate, OCTAPACE Culture and HRD mechanisms.

The table under reference shows that the general climate for HRD Climate in VTPS is more conducive than KTPS. It is evident from the average values obtained in two power plants under study. For instance, the average value for general climate in VTPS has been computed 3.94 (73.50 percent) and the corresponding value in the KTPS is 3.64 (71.00 percent). Hence, there is negligible variation to the extent of two per cent in general climate between the two power plants. The comparative average mean values in the VTPS and KTPS for OCTAPACE culture have been arrived at 3.92 (73.00) and 3.85 (71.25) respectively. Therefore, there exists only 0.07 (1.75) of difference in the OCTAPACE culture between the two organizations under study, which is quite negligible. Regarding the variable HRD mechanisms the average values in the VTPS and KTPS have been computed at 3.91 (72.75 percent) and 3.86 (71.50 percent) respectively. Therefore, there exists 1.25 percent of difference in the HRD mechanisms between the two organizations surveyed, which is quite negligible. Hence, the degree of overall development climate in VTPS is slightly higher than that of KTPS. However, the overall developmental climate in both the power plants is satisfactory.

Table 4: Comparative Position of Executives and Non-Executives in VTPS and KTPS

\begin{tabular}{|l|c|c|c|c|}
\hline \multirow{2}{*}{$\begin{array}{c}\text { Categories of } \\
\text { Employees }\end{array}$} & \multicolumn{2}{|c|}{ VTPS } & \multicolumn{2}{c|}{ KTPS } \\
\cline { 2 - 5 } & Mean & \% & Mean & \% \\
\hline Executives & 3.95 & 73.75 & 3.85 & 71.25 \\
\hline Non-Executives & 3.91 & 72.75 & 3.84 & 71.00 \\
\hline
\end{tabular}

Source: Primary Data

The Table 4 displays the comparative level of development climate at different levels, according to the mean values and percentages scores regarding the HRD Climate obtained in the two selected organizations.

The table shows that the HRD climate at executive level is more or less equally conducive in VTPS and KTPS. It is evident from the average values of the two plants obtained in the executive category. Whereas the average values of the VTPS in the said category has been computed at 3.95 (73.75 percent) and the corresponding mean value for the KTPS is 3.85 (71.25 percent). A perceptual difference of two percent is recorded between the two organizations at executive level. The comparative average mean values of VTPS and KTPS as regards the non-executives are 3.91 (72.75 percent) and 3.84 (71.00 percent) respectively. Hence the level of perception is equal in this category in both the organization if the minute percentage difference of 1.75 is ignored, which of course does not show any impact on the comparative analysis. 
Table 5: Overall Mean Values of HRD Climate in the Selected Organizations

\begin{tabular}{|l|c|c|c|}
\hline Organisation & General Climate & OCTAPACE Culture & HRD Mechanisms \\
\hline VTPS & 3.94 & 3.92 & 3.91 \\
\hline KTPS & 3.84 & 3.85 & 3.86 \\
\hline
\end{tabular}

Source: Primary Data

\subsection{ANOVA One Factor Analysis in KTPS}

\section{NULL HYPOTHESIS}

H0: There is no significant difference between elements of HRD climate in KTPS.

Table 6: Summary

\begin{tabular}{|l|c|c|c|c|}
\hline \multicolumn{1}{|c|}{ Groups } & $\begin{array}{c}\text { No. of } \\
\text { Items }\end{array}$ & Sum & Mean & Variance \\
\hline General Climate & 13 & 49.93 & 3.84 & 0.20 \\
\hline OCTAPACE Culture & 10 & 38.51 & 3.85 & 0.05 \\
\hline HRD Mechanism & 15 & 57.91 & 3.86 & 0.07 \\
\hline
\end{tabular}

Table 7: ANOVA

\begin{tabular}{|l|c|c|c|c|c|}
\hline Source of Variation & $\begin{array}{c}\text { Sum of } \\
\text { Squares }\end{array}$ & df & $\begin{array}{c}\text { Mean } \\
\text { Square }\end{array}$ & P Value & F \\
\hline Between Groups & 0.00 & 2 & 0.00 & 0.01 & 3.26 \\
\hline Within Groups & 4.08 & 35 & 0.11 & & \\
\hline Total & 4.08 & 37 & & & \\
\hline
\end{tabular}

Since $p>0.05$ the Null Hypothesis is accepted at $5 \%$ level of significance. Hence it is concluded that there is no significant difference between elements of HRD climate in KTPS.

\subsection{ANOVA Single Factor Analysis In VTPS}

H0: There is no significant difference between elements of HRD climate in VTPS.

Table 8: Summary

\begin{tabular}{|l|c|c|c|c|}
\hline \multicolumn{1}{|c|}{ Groups } & $\begin{array}{c}\text { No. of } \\
\text { Items }\end{array}$ & Sum & Mean & Variance \\
\hline General Climate & 13 & 51.25 & 3.94 & 0.22 \\
\hline OCTAPACE Culture & 10 & 39.23 & 3.92 & 0.03 \\
\hline HRD Mechanism & 15 & 58.67 & 3.91 & 0.08 \\
\hline
\end{tabular}

Table 9: ANOVA

\begin{tabular}{|l|c|c|c|c|c|}
\hline Source of Variation & $\begin{array}{c}\text { Sum of } \\
\text { Squares }\end{array}$ & Df & $\begin{array}{c}\text { Mean } \\
\text { Square }\end{array}$ & P-Value & F \\
\hline Between Groups & 0.00 & 2 & 0.00 & 0.97 & 3.26 \\
\hline Within Groups & 4.21 & 35 & 0.12 & & \\
\hline Total & 4.22 & 37 & & & \\
\hline
\end{tabular}

Since $\mathrm{p}>0.05$ the Null Hypothesis is accepted at $5 \%$ level of significance. Hence it is concluded that there is no significant difference in elements of HRD climate in VTPS. 


\subsection{Analysis of HRD Climate in Study Organisations}

\section{NULL HYPOTHESIS}

H0: There is no significant difference between HRD climates in study organisations.

Table 10: Summary

\begin{tabular}{|l|c|c|c|c|}
\hline \multicolumn{1}{|c|}{ Groups } & No of Items & Sum & Mean & Variance \\
\hline General Climate & 13 & 7.43 & 3.71 & 0.08 \\
\hline OCTAPACE culture & 10 & 7.77 & 3.88 & 0.00 \\
\hline HRD Mechanisms & 15 & 7.48 & 3.74 & 0.05 \\
\hline
\end{tabular}

Table 11: ANOVA

\begin{tabular}{|l|c|c|c|c|c|}
\hline Source of Variation & Sum of Squares & Df & Mean Square & P-value & F Value \\
\hline Between Groups & 0.03 & 2 & 0.01 & 0.72 & 9.55 \\
\hline Within Groups & 0.14 & 3 & 0.04 & & \\
\hline Total & 0.17 & 5 & & & \\
\hline
\end{tabular}

Since $p>0.05$ the Null Hypothesis is accepted at $5 \%$ level of significance. Hence it is concluded that there is no significant difference between the factors of HRD climate in the study organizations.

\section{FINDINGS}

It is evident from the study that the total management does not go out of the way to help its employees. But at the same time these two organisations believe that human resources are more important and treat more humanely. The most important finding in this study is that the managers of both organisations felt that the development of the subordinates is an important part of their job. It is observed that executives and non-executives strongly agreed that the personnel policies of the organisation facilitate employee development. In VTPS and KTPS seniors not only help their juniors to learn their job but also to develop their competencies. The team spirit is very high in the organisations. Overall general climate is fine.

Mutual trust among the employees is one of the factors that determine the organisation. In nutshell it is found that of HRD culture of the organisation is satisfactory.

A very good reward system and promotion system is existing in VTPS and KTPS. Opportunity to try out what they learn through training is also satisfactory. Employee welfare and employee development is satisfactory.

\section{SUGGESTIONS}

It is drawn from the study that VTPS and KTPS are moderately utilising the potential of the employees. There is substantial scope for utilising the potential of the employees. It is recommended that the management should make efforts to identify potential and utilise them at the optimum level. For this purpose, it is advised to develop competency mapping for the proper utilisation of it.

Since both VTPS and KTPS are public sector units it is difficult to the management to go out of its way to help the employees. In spite of that it is suggested that management can help the employees informally. It can be done without disturbing the organisational interests. It will not only motivate the employees but also create the confidence among the employees. It will lead to increase in the level of performance and in turn into productivity. 
The managements of VTPS and KTPS treat their employees as the most valuable resources and treat them more humanely. So, it is suggested that the managements of KTPS and VTPS should continue the same way so as to increase the productivity further.

Development of subordinates is seen as an important part of their job by managers in VTPS. They identify the performance of the employees through appraisal reports and suggest them for training. In the case of KTPS, the level of interest of management in the development of subordinate is moderate. So, it is advised to the top management of KTPS, the management should take care of the development of the employees by identifying their strengths and weaknesses. Managers should provide necessary suggestions

The top managements of VTPS and KTPS invest time and other resources for the employee development. VTPS conducts training programmes for the employees of various categories. KTPS also invests the money and time for the development of the employees. So, it is suggested that the managements of VTPS and KTPS should continue the existing practice for employee development.

Management in VTPS and KTPS believe that the behaviour of people can be changed and people can be developed at any stage of their life time. This is due to the fact that employees in both the power plants are highly educated and knowledgeable. They can understand that the change is permanent and through change only development is possible. So, it is advised to the management to maintain the existing climate in the present process by creating awareness about the need of transparency and openness.

It is drawn from the conclusion of the study that VTPS and KTPS are moderately utilizing the potential of the employees. There is substantial scope for utilizing the potential of the employees. It is advised that management should make efforts to identify potential and utilize them at optimum level. For this purpose, it is advised to develop competency mapping to make proper utilization of it.

The managements of VTPS and KTPS rewards the hardworking and competent employees. The employees are rewarded very richly if the works are completed on time, or before time. At the same time the highly performing employees are appreciated with certificates of appreciation. In this regard, it is suggested to the managements of VTPS and KTPS to continue the existing reward mechanism. It motivates employees and differentiates between performers and nonperformers.

It is drawn from the conclusion that superiors in KTPS and VTPS show moderate interest to praise the good work done by their subordinates. There is a lot of scope to improve this HRD mechanism in two power plants. In this regard, it is suggested to the managements of VTPS and KTPS that they should develop a culture where superiors should recognize good works done by the employees and praise them. The effective execution of this HRD mechanism would increase employee loyalty in the two power plants.

\section{CONCLUSIONS}

Human Resource Development climate (HRDC) in both VTPS and KTPS is very good. The top management of both organisations are supporting for good HRD environment. The success of VTPS and KTPS is possible only because of their human resources. It is concluded that the HRD Climate plays a pivotal role in achieving the goals of the organisation. Organisational success depends largely on the quality of their human resources depends on the prevailing organizational developmental climate. Organisations must ensure that an optimal level of Human Resource Developmental Climate 
(HRDC) exists to enable their employees to discover hidden potentials, improve on their current skills and acquire new relevant skills and utilize them in the interest of their organisations. Therefore, HRD is the key to enhance and effective utilization of intellectual, technological and entrepreneurial skills of human resources.

\section{REFERENCES}

1. Alexander Ardichvili and Alexander Gasparishivili, (2001) "Human Resource Development in an Industry in Transition: The Case of the Russian Banking Sector", Human Resource Development International, Vol. 4, No.1, pp. 47-63.

2. Alphonsa, V.K, Sr., (2000), HRD Climate in a Private Hospital in Hyderabad-An Empirical Study, IJTD, Vol.XXX (4).

3. Agarwala Tanuja, (2002) "Innovative Human Resource Practices and HRD Climate: A Comparison of Resource Development in Asia”, Oxford \& New Delhi.

4. Amitabh Kodwani, Abhinaya, C and Swapnika, C, "Training and development Practices: A Study in Indian Public Sector Banks" The ICFAI Journal of Organisational Behavior, Vol.IV, No.1.

5. Anukool M. Hyde and Sanjyot Pethe, (2005) "Impact of Human Resource Development Climate on Empowerment and Organization Citizenship Behavior" The ICFAI Journal of Organizational Behavior, Vol. IV, No3.

6. AshitK.Sarkar, (2003) "Performance Based Award Scheme" Personnel Today, Vol. XXIII, No. 4, pp. 43-45.

7. Ashit K.Sarkar (2004) "Employee Development Beyond Training" personnel Today, Vol. XXV, No.1, pp.19-20.

8. Benarjee, B.B.R.N.K., and Roja Rani, E., (2004) "New Perspectives of Quality Of Work Life", The Indian Journal of Commerce, Vol.57, No.1, pp.73-81.

9. Catterjee, D.D, (2003) "Sharing and Caring of Human Resource", Personnel Today, Vol. XXIV, No.1, pp.24-26.

10. Chakravarthy, E. Ajantha, (2002) "Corporate HRD Whatever Manager Should Know About Human Resource Development" Crest Publishing House, New-Delhi, pp. 204-213.

11. Chalam, G.V. and Srinivas, L. (2005) "Gender-wise Perceptions and Attitudes on Human Resource Development Climate in Indian Banking Sector" Indian Journal of Commerce, Vol. 58, No. 4, , pp. 62-71.

12. Madolli, M. J., Kanannavar, P. S., \& Ravindra, Y. (2015). Impact of climate change on precipitation for the upper Cauvery river basin, Karnataka state. International Journal of Agricultural Science and Research (IJASR), 5(1), 99-104.

13. Dolai, D. (2015), Perception of employees on HRD climate in insurance sector.”4 (7), pp. 328-330

14. Farooq A. Shah, (2003), "Role Stress in the Indian Industry: A Study of Banking Organizations", Indian Journal of Industrial Relations, Vol. 38, No. , p. 281.

15. Geeta Gupta, (2003) "Human Resource Development and Human Units", HRD Times, Vol. 5, No. 3,,pp. 9-11.

16. Grieves, Jim, (2003) "Strategic Human Resource Development", Sage Publications India Pvt. Ltd., New Delhi, p. 91.

17. Goyal, K.C., (2004) ."Human Resource Development Strategies in Power Sector Undertakings in India", The Indian journal of Commerce, Vol.57, No. 3,, pp.234-237.

18. Kndula, R. Srinivas, (2001) "Strategic Human Resource Development", Prentice Hall of India Private Limited, New Delhi, p. 106.

19. Kumudha, A., \& Abraham, S. (2008) "Organisation career management and its impact on career satisfaction: A study in the banking sector”, ICFAI University Journal of Bank Management, 7(3), 71-84. 
20. AHMED, C. I., HU, W. B., \& KUMAR, S. (2016). Indigenous knowledge about prediction in climate change. International Journal of Humanities and Social Science, 5, 45, 62.

21. Kumar, Sharad and Patnaik Sabita.P., (2002) HRD Climate and Attributes of Teachers in JNVS, IJTD, XXXII, (2) Apr. June P 31-37.

22. Lelyn L.K. Roudrigues, (2005) "Industry - Institute Correlate of HRD Climate: Empirical study based Implication", Indian Journal of Industrial Relations, Vol. 41, No. 2, pp. 167-168.

23. Mufeed S.A (2006) "The Need for a Focus on Key Elements of HRD Climate in hospitals- An Empirical Study, Management of Labour Studies XLRI, Jamshedpur Vol.31PP57-65.

24. Mufeed, S. A., \& Hamdani, Q. A. (2013) "HRD mechanisms in health care sector in Jammu \&Kashmir: A comparative study", European scientific journal, $9(21)$.

25. Nayak, N.G., (2003) "Performance Appraisal- A Study", Personnel Today, Vol.XXIV, No. 2, pp.3-10.

26. Omer Bin Sayeed and Bhide, P.V., "Performance Appraisal Effectiveness: An Empirical Assessment", Indian Journal of Industrial Relations, vol.39,No.2, October 2003, pp.166-181.

27. Pdmakali Mishra and Gopa Bharadwaj, (2002) "Human Resource Development Climate: An Empirical Study Among Private Sector Managers", Indian Journal of Industrial Relations, Vol. 38, No.1, pp.66-80.

28. Patel, M.K., and Bhuvana, K.Iyer, (2004) "HRD General Practices in Drugs and Pharmaceutical Industry", The Indian Journal of Commerce, Vol.57, N0.1, pp.86-91.

29. Priyadarshini, Geetha. Ravi. $R$ and Venkatapathy. (2004) Impact of HRD on Organizational effectiveness in the Banking Industry, Prajnan, Vol XXXII (2) PP135-147.

30. Dash, Srinibash., Mohapatra, J., \& Bhuyan, L. (2013). A Correlation of HRD Climate with Job Satisfaction of Employees: An Empirical Investigation on MCL, Burla, Sambalpur, Odisha. International Journal of Research in Business Management (IJRBM), 1(2), 11-26

31. Pranabesh Ray (2004), "The Essence of Human Resource Development", Personnel Today, Vol. XXIV, No.4, pp. 11-13

32. Prakasha Rao, B.K.S. and Venkateswara Rao, B.H. (2005) "Human Resource Sri Vastava,V.N. and Ghosh, K.(2005) "Challenges of HRM and HRD - Emerging Paradigm", The ICFAI Journal of Organizational Behavior Vol. IV, No. 4, pp.8182.

33. Rajeshwari Narendran and Narendran, (2003), “ IT Revolution: Challenges for Human Resource Development, "Indian Journal of Training and Development" Vol. XXVI, No.2.

34. Saraswathi, S., (2010) “Human Resources Development Climate: An Empirical Study”, International Journal of Innovation Management and Technology, 1(2), pp. 174-179

35. Srinivas, B.S.S., (2005) "HRD Practices in the Software Industry: A Study with Special Reference to Software Companies in Hyderabad", GITAM Journal of Management, Vol.3, No.1, , pp.247-250.

36. Upinder Dhar, (2004) "Career Planning as a Mechanism of HRD", University News, 42(29), p. 12 \& 16. 
